\begin{tabular}{c} 
Volume and Issues Obtainable at Center for Sustainability Research and Consultancy \\
Journal of Business and Social Review in Emerging Economies \\
ISSN: 2519-089X (E): 2519-0326 \\
Volume 6: No. 3, 2020 \\
CSRC \\
Journal homepage: www.publishing.globalcsrc.org/jbsee \\
\hline
\end{tabular}

\title{
Temporality: Living Through the Time While Doing Doctoral Studies
}

\author{
${ }^{1}$ Syed Abdul Waheed, ${ }^{2}$ Nadia Gilani, ${ }^{3}$ Mehwish Raza
}

${ }^{1}$ Assistant Professor, Department of Educational Research \& Assessment, University of Okara, Okara Pakistan, s.a.waheed@uo.edu.pk

${ }^{2}$ Assistant Professor, Department of Teacher Education, University of Okara, Okara Pakistan, nadia.gilani@uo.edu.pk

${ }^{3}$ Assistant Professor, Dean, Faculty of Education, Forman Christian College (A Chartered University), Lahore

Pakistan, mehwishraza81@gmail.com

\begin{tabular}{l}
\hline ARTICLE DETAILS \\
\hline History \\
Revised format: August 2020 \\
Available Online: September \\
2020 \\
\hline Keywords \\
Doctoral students, university, \\
time, temporality, lived \\
experience, study abroad.
\end{tabular}

\section{JEL Classification}

MO, M40

\begin{abstract}
Doctoral students' experiences of stay and study abroad determine how they experience and understand time in relation to other existential themes of body, space, and relation. The present study aimed to understand what meanings doctoral students' assign to time while doing their doctoral studies in different public universities of Austria. Thirteen participants were recruited purposively to understand how did they experience time and how did their experience of time determine the way they live and study in a university and complete their doctoral studies. The questions were explored through conducting and recording the interviews in a semi-structured form and subsequently transcribing and analyzing the transcripts. The participants experienced that time continuously shaped their life experiences with respect to the space they lived in, relationality, and corporeal experiences. The students experienced time as an agent of pressure, perceived as being slow or fast in their studies, feeling connected or disconnected with their family, work and study and a tool to gauge their work performance and completion of their studies. The study has a phenomenological significance of understanding of time as experienced by a group of doctoral students that led to the way they lived, stayed and studied abroad.
\end{abstract}

(C) 2020 Center for Sustainability Research and Consultancy Pakistan under a Creative Commons Attribution-NonCommercial-ShareAlike 4.0

Corresponding author's email address: $\underline{\text { s.a.waheed@uo.edu.pk }}$

Recommended citation: Waheed, S. A., Gilani, N. \& Raza, M. (2020). Temporality: Living through the time while doing doctoral studies. Journal of Business and Social Review in Emerging Economies, 6(3), 1111, 1117

\section{Introduction}

Doctoral students constitute one of the most influential group of student communities in academia and their teaching and learning experiences as beginner teachers and early career researchers distinguish them from other academicians and researchers in the universities. Doctoral students' academic and social life help them integrate and benefit from the research culture in a university environment. Phenomenologically, they have various lived experiences of space, body, relationality and time while working in an educational or research institute. In phenomenological perspectives, time is not deemed as it is perceived in the form of clock time such as series of seconds, minutes and hours, but it is considered as a 'network of intentionalities' experienced and perceived by the human being in a situation.

Lived time or temporality is a subjective experience lived through in a socio-cultural context (van Manen, 1997). 
Merleau-Ponty (1962) reflected, "A perceptual field is a field in which perceptions are present in time and space" (p. 478). Van Manen (1997) added that "lived time is a time that appears to speed up when we enjoy ourselves or slow down when we feel bored during an uninteresting lecture or when we are anxious as in the dentist's chair" (p. 104). Einstein elaborated temporality with a classic example. He remarked, "When a man sits with a pretty girl for an hour, it seems like a minute. But let him sit on a hot stove for a minute - and it's longer than an hour. That's relativity". Moreover, Merleau-Ponty (1962) argued, "When individuals recall a remote past, they reopen time and carry themselves back to a moment in which it still had before it a future horizon now closed, and a horizon of the immediate past which is today remote" (p. 483).

Students describe their experiences in terms of time, space, body or relationality. They live through a period at different stages of their studies in an educational environment and they experience time in different ways during these socio-academic situations in the context of the institute and country where they live and study. Experiencing time in an academic situation reflects how students perceive environment while assigning meanings to the time and how does it relate to their life and studies. These experiences vary across the program of studies, institutions, individuals and countries. The experiences may be interpreted in two aspects: in relation to other students and the context of the educational environment.

Many research studies related to doctoral students focused on academic and social integration, retention or persistence, the drop-out, academic success and achievement and learning satisfaction (Astin, 1978, 1984; Pascarella \& Terenzini, 1991; Tinto, 1993, 1997). Moreover, many other studies researched doctoral students' persistence in different academic programs such as persistence of doctoral students-- in mathematics (Earl-Novell, 2006; Herzig, 2002), distance education (Ivankova \& Stick, 2007), counselor programs (Hoskins \& Goldberg, 2005), education studies (Spaulding \& Rockinson-Szapkiw, 2012), and studies on female doctoral candidates (Castro, Garcia, Cavazos, \& Castro, 2011; Maher, Ford, \& Thompson, 2004) and dropped-out doctoral students (Golde, 2005).

Nevertheless, there is a scarcity of literature on understanding doctoral students' life in socio-academic settings and particularly their lived time in educational culture. In the present study, an attempt was made to grasp an understanding of how doctoral students lived through the time while confronting different socio-academic situations in Austrian universities and what meanings they assigned to experiencing time in an academic environment. This perspective of doctoral students' journey towards the completion of their studies led to the following research questions:

1. How did doctoral students experience time while doing a doctorate in different fields of studies in the context of various universities?

2. How did doctoral students' experience of time determine time-pressure and their understanding of the completion of their studies?

\section{Methodology}

The study was undertaken using a phenomenological approach to qualitative research. Semi-structured face-to-face interviews of 43 to 67 minutes were conducted with thirteen participants. The sample was drawn from a large group of Pakistani doctoral scholars studying at Austrian universities in various disciplines. Purposive sampling was used to recruit the participants. The study is significant because the participants were living abroad, away from their native country and occupational place and working in different universities that shaped their experiences of temporality in another academic and social culture. Demographic information was collected through a questionnaire before the start of the interview. The interview protocol consisted of questions that captured their lived experiences of time in a different setting and circumstances according to the research questions of the study. Each interview was audiorecorded after taking permission from the participants and then transcribed by the researchers.

According to Husserl (1964), there is a clear difference between the time on the clocks or calendars and the time experienced by our consciousness in a specific context when analyzed phenomenologically. This analysis helps understand time with the temporal structure of that particular event (Husserl, 1964). In a way, a phenomenon is shaped and structured by the participants' experiences, interpretations and understanding of time (Van Manen, 2006). 
The study takes on phenomenological analysis describing the meanings the participants assigned to their experiences and understanding of time analyzed from the transcribed interviews. The meanings assigned and interpreted by the participants were the crux of experiences of time and they connected the meanings and significance associated with that particular experience.

\section{Results}

Time was an essential factor for doctoral candidates during their studies. Most of the doctoral candidates experienced that they had 'sufficient time' when they were enrolled in the first semester and they experienced a state of comfort due to the feelings of having 'enough time' in the beginning. Doctoral students described various experiences of lived time in different situations and academic settings that determined how they continued their journey towards their research and studies.

\section{Being Slow or Fast}

Conducting and reporting research is the core activity in doctoral studies and it is time-taking, particularly when doctoral students are engaged in conceptualizing and developing the research plan in the beginning few semesters. Doctoral candidates experienced lived time in their own way while researching. One example was described by Maryam who experienced time as a 'source of pressure' that influenced her academic and family life. She elaborated that developing a research proposal is a tedious job due to the pressure of 'limited time'. She described, "two years is much time for developing and publishing research proposal and it is tough to live through this time as you face much criticism and many challenges.... sometimes unnecessarily."

She experienced time as an element of pressure before starting her $\mathrm{PhD}$. She was left alone among her colleagues who had gone abroad to pursue their PhDs and she was feeling like 'time is running fast,' and she is not pacing herself with the time. She realized, "I am wasting time, it is high time to do a PhD" and under this time pressure, she decided to pursue her $\mathrm{PhD}$ in a country where she did not want to go. Also, she had to study extra courses of Master and Bachelor studies before starting her PhD semester and it served as an added pressure due to the stipulated time for completing PhD under a scholarship program. She reflected:

I was under tremendous time pressure because I had to pass the required Bachelor and Master course of compulsory studies to get enrolled in the $3^{\text {rd }}$ semester of PhD. The PhD studies here is very systematic and sequential in a way that you cannot move forward unless you complete on a step.

Submission of research papers to the journal and projects to funding agencies involves deadlines and time constraints that put doctoral candidates under pressure. Daud experienced as if time was passing very quickly and there were many deadlines to be met. He was wondering that if he would be in a position to complete his PhD well in time, or he would be required an extension in time. In the beginning, he had much time that allowed him to make experiments and explorations in his field of study. He thought that he could 'play independently' and 'try the things differently' that might waste time but would be a source of learning independently.

Managing time led the participants to how they manage family and studies that make them happy or unhappy, restricted or relaxed, pleasant or unpleasant. Haris was a doctoral candidate who was working in a research institute while living with his small family. He was managing time in a way that could allow him to maintain a balance between family, work and studies. Nevertheless, he could not participate in most of the academic and research activities in the university where he was enrolled as a doctoral student. He described:

We have to work in the institute and have to spend time with family that makes it difficult to visit the university on a regular basis and engage ourselves in the activities of the department. It seems that time has restricted us to the workstation that has deprived me of many useful things that happen in the department.

Time restricts someone to a place and it gives pleasure to others while deeply engaged in their studies and isolating themselves from the outer world. Ilyas described such experiences. He reflected: 
I work tremendously well in time pressure. My concentration is enhanced, my focus is sharpened and the quality of work is much improved. I am lost in time and cut from the outer world. I feel like I am deeply engaged and don't know what is happening outside. I don't know ... it feels like timelessness.

\section{Time and Work}

The understanding of time was associated with the pace of work by doctoral students. Some doctoral students were restricted by the external environment that gives them feelings of "confining within the boundary of four walls" and thus, they feel like time has stopped for them and they experience themselves as 'unproductive'. One of the participants named Yousuf, who was studying in a veterinary university, described:

My boss wants me to be here in this office from morning till evening, even if I don't have something to do. This restricts me to this office and I feel like time is static like me. I feel like I have no energy and no motivation and time has confined me physically and spiritually.

This situation of aimlessness made some of the participants feel that their capabilities and quality of work is negatively affected. Yousuf elaborated, "My efficiency is improved if I have more time to achieve my objectives. I can't do well if my Boss gives me deadlines to meet targets. This can reduce my energy and motivation." He reflected that a Boss could behave like a friendly father or like a Villain. Most of the time, a Boss behaves as a father who has his own authority, pressure and influence in a house.

There were doctoral students who were researching in the field of engineering, science and technology and they were working in the laboratories for longer hours. Some of them worked overnights being away from their families. Yaqoob was such a doctoral candidate in Engineering and he reflected, "Time passes very slowly when I am experimenting in the laboratory. I fix my eyes on the clock and keep watching when the experiment comes to an end. It seems it will never reach to its destination." Yasmin was in the sixth semester in a similar field when she was interviewed, and she reflected:

I can say that time was very slow in the start of the first semester. Also, I had selected a different field of research and I did not have much knowledge in this field. The uncertainty of success in this new domain slowed me down and time was slow too...Now, I wish that the time would stop but it doesn't... It is running out and I have much to do.

Working from an area of study unknown to the doctoral candidates gives a different experience of temporality. Yasmin, who was doing doctoral studies in one of the fields of computer science, had started her studies after a long interval of time since she graduated from the university. She changed her interest to research in different fields of study. She wanted to have much time for exploration of the new domain of study. She experienced:

My supervisor is changed but I don't want to make another beginning. Time would not support me this time if I changed my field of study with the change of supervisor. I want to move ahead with the time. I would be required much time if I have to work from the beginning again. I don't think I should do so.

There were other students who were feeling comfortable in the beginning of their doctoral journey and time was like a "vast field to play for a long time". One such student was Yaqoob, who was feeling a tense situation in the start of his studies because he was making very slow progress but later, he thought that there was much time ahead and this perception of having sufficient time "healed his tension". The time passed on and he was feeling much relaxed after changing the topic and making progress speedily that gave him a sense of compensation of the little work done in the beginning.

Salman was a student who was working in a laboratory and intended to publish more in relatively less time. He was expecting things to happen at a much faster pace. He imagined that he would be able to perform computational work quickly, having results in hand and chemicals would be tested in another university. Resultantly, he would be able to get his work published faster. In practice, it could not be done because the other university have to spend much time 
in testing his computationally designed model. He experienced, "The first two years of PhD were much comfortable ... but it was hard to carry on from the third year because there was much to do and it was hard to live through the time."

\section{Time and Studies}

Time heals and leads to further success and happiness. Younus has not a good idea of what to do and how to do with a little help or no help within the institute for publication of papers. The idea of the topic for his PhD thesis evolved much slowly because he did not have a great knowledge of that area, but it worked slowly and, in the end, resulted in great success and happiness. In the absence of appropriate guidance within his university, he kept on vetting his ideas for further exploration through a peer review process that helped him in the long to understand what he should do and what he could do. Like many other PhD students, he had limited funding. He reflected, "When I think about the remaining one or one and a half years to finish my PhD, I feel the pressure of time and it affects my daily life negatively." The understanding of time was "requirement driven," and it depends on "the expectations of the supervisor... and how the expectations are met."

The perception and experience of time were not the same for all of the participants of the study. The different stages of $\mathrm{PhD}$ changed the perception of time as well. Ismail had a philosophical way of thinking about time. He reflected, "Now I am sitting at the other end of the time. When I look back, I relate the speed of time with the progress in my work somehow. The time was slow for the last three years and there was more progress in terms of my 'development'." This was an understanding of time in view of one's progress of research, 'personal development', a specific situation or the academic culture of the university where the students spend most of their time. Also, students' collegial relationships with other fellows and professionals determined the way they experienced the time.

Sara's understanding of living through the time during her academic and research activities was "openly based on the subjective interpretation of her thoughts." At the initial stage, she was more inclined towards sharing a collaborative platform with other fellow artists at the university and thought that she would be "mechanically integrated," but despite a very "methodical process of integration," she felt a little bit distant and alien to the whole system with little and no understanding of current surroundings and happenings. At a later stage, she was appreciated for her work that increased her belief in herself and in time. She remarked that "fortunately enough I presented my work at three different places on three different stages and believability of time increased as I became appreciated and recognized, which eventually pulled me out of the self-constructed aura." She remarked conclusively that "my discourse of perception through time in the context of my doctoral studies has taught me to 'do and get it'- where enthusiasm should not be only registered as taking but experiencing and experimenting."

Wastage of time was a function of feelings that doctoral students were able to do nothing in a given time period. This led them to feelings of anxiety and helplessness. Yaqoob was a doctoral student who had to change his topic for conducting research after spending a couple of semesters in the university and studying a lot in the previous area. Even then, the time for starting to experiment for his research was not over. He had to wait for another year for the installation of the required equipment, its functioning and learning to handle it. The time this was realized him for having a decreased sense of motivation and deprivation. In response to his experience in this situation, he described, "I felt angry, but we could do nothing except 'control' ourselves... because we are living in a foreign country."

\section{Discussion}

Lived time or temporality is the subjective experience of time in a specific context (van Manen, 1997). This is participants' reflection of time. In the present study, doctoral students experienced time in their own perspectives in the context of a specific university environment while passing through different stages of studies that determined their understanding of body, space and relationality as well. It was noticed that doctoral students experienced that they had sufficient time in the beginning that made them more relaxed as compared to the later stages of their studies. In other words, the time was experienced in their specific context or the situation they were living in.

Time pressure was experienced as an influencing factor for many doctoral students in the present study. Maryam was one of the doctoral students who was 'terrified' of time pressure and realized that it could hinder her study progress if 
she could not meet the target of completing the pre-requisite courses for $\mathrm{PhD}$. She reflected, "It is a great pressure because it is very sequential. If you finish one step, only then you can proceed to the next one". Meeting deadlines was another aspect of time perception. Daud, a doctoral candidate, experienced the pressure of deadlines when he had to submit the research paper to the journal. He used to think, "Will I be able to complete my PhD within the funding period"? He considered that time for funding determines the perception of time as well. On the other hand, some of the students felt out of the box of time and did not feel pressure throughout the doctoral journey. Yusouf elaborated, "I can work in a better way if I have free time... Also, my boss has his own natural pressure as a father has in the house... One cannot do work when the boss is very harsh". Also, time joined and disconnected PhD scholars. Haris was of the view that I was connected with family, work and studies through the string of time and I had experienced a bond among these due to a specific experience of time. Yousuf described, "If you have nothing to do, you are wasting your energy, one should go and enjoy that time..."

Working in the laboratories for long hours was a unique experience for all doctoral students from the fields of engineering, science and technology. Yaqoob experienced, "I feel like time is passing very slowly because you are sitting all the time and watching that [equipment]. You can do nothing other than this". The perception of time was not soothing and a source of comfort when his work was prolonged in the beginning. Thus, time was healing, pleasant, unpleasant, stressful and irritating at different times. In accordance with such experiences, van Manen (1997) argues that lived time "appears to speed up when we enjoy ourselves, or slows down when we feel bored during an uninteresting lecture or when we are anxious as in the dentist's chair" (p. 104). In other words, quoted by Albert Einstein, "When a man sits with a pretty girl for an hour, it seems like a minute. But let him sit on a hot stove for a minute - and it's longer than an hour". Also, Flaherty (1999), "any form of suffering is capable of provoking the perception that time is passing slowly" (p. 43).

Other participants of the study, such as Yasmin who was in the third year of her doctoral studies, experienced, "in the beginning, time was running very slowly and I didn't worry about finishing my task... Now, I wish that the time should stop, but it doesn't... It is running out, and I have much to do". This time perception was reflected by Merleau-Ponty (1962). He stated, "When individuals recall a remote past, they reopen time and carry themselves back to a moment in which it still had before it a future horizon now closed, and a horizon of the immediate past which is today remote" (p. 483). van Manen (1997) was of the view that "the temporal dimensions of the past, present, and future constitute the horizons of a person's temporal landscape" (p. 104). Also, Flaherty (1999) delineates the paradoxes hidden in a perceived span of time and explained it with instances of lived experiences. He asserts that time is perceived as having slowed down "in situations with abnormally high or abnormally low levels of overt activity" (p. 21).

\section{Conclusion}

Time was experienced in different perspectives by the participants. It made them tense when doctoral students have to do more in a limited time whereas it was relaxing, pleasant and worried-less in the beginning when they viewed that they had 'sufficient time' and most of them were unknown of what will happen during the doctoral journey ahead. Some of the participants imagined that the passed-time should come back while others wished that it should stop for us to complete our delayed work and allow us more passion for doing work without having stress. In some cases, time was perceived as 'requirement driven', depending on the expectations of the supervisor and how these were met while some students related time to the progress of their studies. From the laboratories, time was experienced as the long intervals that never end and one has to keep watching the clock all the time. In an office, it restricted the movements and freedom and decreased motivation to work and study. Time continuously shaped participants' life experiences with respect to the space they were living in, relationality, and corporeal experiences.

\section{References}

Astin, A. W. (1978). Four critical years. San Francisco: Jossey-Bass.

Astin, A. W. (1984). Student involvement: A developmental theory for higher education. Journal of College Student Personnel, 25(4), 297-308.

Earl-Novell, S. (2006). Determining the extent to which program structure features and integration mechanisms facilitate or impede doctoral student persistence in mathematics. International Journal of Doctoral Studies, 1, 45-57. 
Flaherty, G. M. (1999). A watched pot: How we experience time. New York: New Your University Press.

Golde, C. M. (2005). The role of the department and discipline in doctoral student attrition: Lessons from four departments. The Journal of Higher Education, 76(6), 669-700.

Herzig, A. H. (2002). Where have all the doctoral students gone? Participation of doctoral students in authentic mathematical activity as a necessary condition for persistence toward the PhD. Educational Studies in Mathematics, 50, 177-212.

Hoskins, C. M., \& Goldberg, A. D. (2005). Doctoral student persistence in counselor education programs: Studentprogram match. Counselor Education and Supervision, 44(3), 175-188.

Husserl, E. (1964). The Phenomenology of Internal Time-Consciousness. Bloomington: Indian University Press, 1964.

Ivankova, N. V., \& Stick, S. L. (2007). Students' persistence in a distributed doctoral program in educational leadership in higher education: A mixed methods study. Research in Higher Education, 48(1), 93-135.

Pascarella, E. T., \& Terenzini, P. T. (1991). How college affects students. San

Francisco: Jossey-Bass.

Pascarella, E. T., \& Terenzini, P. T. (2005). How college affects students: A third decade of research. San Francisco: Jossey-Bass.

Spaulding, L. S. \& Rockinson-Szapkiw, A. J. (2012). Hearing their voices: Factors doctoral candidates attribute to their persistence. International Journal of Doctoral Studies, 7, 199-219.

Tinto, V. (1993). Leaving college: Rethinking the causes and cures of student attrition (2nd ed.). Chicago: The University of Chicago Press.

Tinto, V. (1997). Classrooms as communities: Exploring the educational character of student persistence. Journal of Higher Education, 68(6), 82.

Van Manen, M. (1997). Researching lived experience: Human science for an action sensitive pedagogy. London, Ontario: The Althouse Press.

Van Manen, M. (2006). Researching the Lived Experience: Human Science for an Action

Sensitive Pedagogy. Winnepeg, Canada: The Althouse Press. 